\title{
Local Dimensions of Global Responsibility
}

\author{
A report from the conference held \\ in the Maria Grzegorzewska University \\ (Warsaw, May 30, 2014)
}

DOI: http://dx.doi.org/10.12775/RF.2015.015

On May 30, 2014 an interdisciplinary academic conference dedicated to local dimensions of global responsibility took place in the Maria Grzegorzewska University in Warsaw. It was already the 7th conference from the "Human Being and the World - Dimensions of Responsibility" series organised by the Chair of Philosophy of Morality and Global Ethics at the the Maria Grzegorzewska University in Warsaw and the Chair of Moral Philosophy and Bioethics at the Nicolaus Copernicus University in Torun.

The leading motto of the conference calls up associations with the commonly known slogan "think globally - act locally." What does it currently mean? Is it realised in practice at all? If so, in what manner? What kind of tensions emerge at the meeting point of the "global" and "local"? What are its limitations? The goal of the conference was a search for answers to the flagged up questions and the main emphasis was put on their axiological background, their link to the problems of global responsibility, and the assumptions of global education. By setting the framework for discussion with the use of the "local - global" opposition the organizers wanted to confront with each other various ways of thinking and perspectives: philosophical-ethical, pedagogical, psychological, social, ecological, political. 
At the conference thirty five papers addressing the problem of the relation between globality and locality were presented. Apart from the plenary session and panel discussion there were four simultaneously working sections divided into six thematic areas: ecology - the local and social aspects; global education; responsible urban planning; dimensions of global responsibility; digital society - dimensions of responsibility; local involvement as a response to the challenges of the globalised world. Among the prelectors there were reputable specialists as well as people who research and implement particular solutions in local areas. In accordance with the organisers' intention the title issue was considered at the meeting point of the theory and practice of the human action.

In the conference's opening plenary session the presentations were given by Prof. Włodzimierz Tyburski (the Chair of Moral Philosophy and Bioethics, Nicolaus Copernicus University in Toruń), Prof. Maria Ledzińska (Department of Psychology of Individual Differences, Warsaw University), Prof. Andrzej Papuziński (the Chair of Policy of Sustainable Development, Kazimierz Wielki University in Bydgoszcz), and Prof. Andrzej Kiepas (the Chair of Philosophical Anthropology and Philosophy of Civilisation, University of Silesia). The majority of problems addressed in the presentations referred to sustainable development and correlated with it global responsibility and values such as solidarity, communion and justice. Particular authors focused on discussing various assumptions underlying sustainable development. Włodzimierz Tyburski's lecture: Local and Global Dimensions of Environment Protection from the Perspective of Responsibility referred to the current ecological thought and linked the notion of responsibility with the categories of ecological crisis and ecological exclusion. Andrzej Kiepas in his presentation: Ethics of Globalisation and Its Limitations invoked the assumptions of "globalisation ethics" formulated by Peter Singer and stemming from them tensions between the local and the global. The issue of sustainable development analysed from the social justice perspective was the focal point of Andrzej Papuziński's paper: Sustainable Development in the Context of Intergenerational Justice Theory. By referring to Rawls' understanding of basic goods the sets of feasible postulates for the current generation towards the future ones was sorted out and clarified. All presented approaches turned the attention to the resulting from local limitations problems in realising the global, and hence striving for universality, principle of responsibility underlying sustainable development.

Another understanding of global responsibility, set forth from the psychological point of view, was presented by Maria Ledzińska. In her lecture: Knowledge about Oneself and the World as a Correlate of Responsibility in the Times of Globalisation - Psychological Perspective responsibility for the future was recognised as a result of a number of cognitive processes focused on creating knowledge about the world and oneself 
that later on translates into actions undertaken in both, the local and global scale.

The motives mentioned in the plenary part were then undertaken, developed and analysed in detail in further speeches taking place during the thematic sessions.

The problems related to eco-philosophy, sustainable development and environmental ethics were broadly discussed (Anna Marek-Bieniasz: Local and Global Dimensions of Ecological Responsibility; Marcin Leźnicki: Local Ecology and the Globalisation of the Contemporary World; Jan T. Mróz: The Care about Ecological Security according to Catholic Social Teaching and International Regulations). There were also references to practical implications of theoretical considerations (Daniela Szymańska, Aleksandra Lewandowska: Biogas Plants in Poland as an Activation Factor for Regional Development), including their local limitations (Dominika Dzwonkowska: Local Responsibility Dimensions: The "Good Climate for Counties" Project as a Compass of Responsibility on the Local Level), cultural drawbacks (Paweł Bernat: Local Cultural Context and Sustainable Development Programmes Implementation: Bedouins from Qasr al Sir - Case Study) as well as societal barriers (Ariadna Ciążela: A Dependency Therapy Centre or a Wind Power Plant? The Attitudes of Young People Towards Ecological Initiatives). The presented approaches showed a discrepancy between theoretical discussion and particular ways and effects of implementing sustainable development and global responsibility postulates.

The issues focused around global education constituted another thematic group. Both, formal and informal ways of carrying out the global education presuppositions in Poland were discussed (Ewa Dąbrowa: The Development of Global Education in Poland from the Perspective of Instilling Responsibility; Kordian Kochanowicz: Global Education in Projects of Polish Non-governmental Organisations - the Goals, Results and Methods of Their Evaluation). Results of the research carried out among Polish teachers of the third educational stage regarding their knowledge about global education and its realisation in the educational process were presented (Ewa Pająk-Ważna: Global Education in Teachers' Opinions - From Interpretation to Implication). The study showed differences in defining and accomplishing the postulates of global education at the gimnazjum level, what was confirmed in the next presentation emphasising the lack of systemic theoretical and practical solutions for global education, especially the one dedicated to people with special educational needs (Urszula Markowska-Manista, Aleksandra Niedzwiedzka-Wardak: Formal and Informal Education in Global Education for Students with Special Educational Needs). To accommodate the mentioned needs the attention was turned to cultural and ethical competences a contemporary teacher should possess and which they should foster in their students (Urszula Dernowska: Global Education at School - from Cultural to Global Competence: 
Teacher's Role and Tasks; Katarzyna Łukaszewska: Axiological Apprenticeship or the Contemporary Educator as a Guide to Applied Ethics). A problem of using the Internet in the educational process was also addressed in the context of the Internet being a tool encouraging to go beyond one's own local responsibility in the direction of initiating actions and activities of the trans-local nature (Piotr Domeracki: Thinking Globally - Acting Locally-Existing in the Network).

Other problems of local implications of global responsibility were addressed by prelectors gathered in the section discussing responsibility of spatial planning. The question was posed how the current problems of Polish cities reflect global tendencies and to what extent they are determined by local conditions. To this end the opinions of Polish and foreign researchers working on problems of the 21st century cities and global cities were confronted (Adam Piotr Zając: Spatial Problems of Polish Cities in the Light of the Chosen Sociological Theories). An attempt was undertaken to decode seemingly axiologically neutral goals underlying the solutions used in managing public spaces on the example of transport organisation in Warsaw (Michał Dobrzański, Piotr Rosół: The Axiology of Space: Unnoticed Dimension of Mobility Management). It was also stated that spatial planning is a significant element of creating spatial order that more and more takes into account local needs and is generated on account of social participation (Aleksandra Lewandowska, Krzysztof Rogatka: Spatial Planning as a Tool of Creating Spatial Order - Chosen Aspects).

Moreover, issues related to local consequences of the economic-political aspects of globalisation were also discusses (Bronisław Treger: Ethics and Globalisation in the Thought of Joseph Stiglit; Krzysztof Michalski: Unsustainable Production and Consumption: Local Dimensions of Global Irresponsibility and Global Dimensions of Local Irresponsibility; Mateusz Kucz: Shared Consumption as a Response to the Dogmas of Neoliberalism; Adam Kubiak: Local Point of View: The Smallest Universalism and the Recurrence of Globality; Katarzyna Lis: The Actions of Transnational Actors - Main Directions, Strategies, Methods; Rafał Jaźwiński: "The Last Man" in the Tight Corner of Liberal Democracy: Pedagogical Implications of F. Fukuyama's Historiosophical Conception) and the development of digital society (Olga Janikowska: The Cosmopolitan Identity in the Era of the Knowledge Society and the Internet; Mirosław Filiciak, Piotr Toczyski: On the TV Content and its Redistribution in the Internet in Europeanizing and globalizing Poland - the "Peer Re-production" and "Extended Culture Industry" Categories; Dagmara M. Boruc: The Dangers of Cyberspace or on Psychological Aspects of Cyber-violence). An alternative was presented to the rather negative discussed consequences of globalisation in the form of on the one hand integrated, based on eco-humanism education of prevalent elites (Eulalia Sajdak-Michnowska, Lesław Michnowski: Wisdom of Elites as a Condition 
for Avoiding Global Catastrophe), and on the other of a project of holistic teaching and learning in the spirit of civil education exercised through People's Universities (Iwona Błaszczak: People's Universities as a School of Modern Regionalism - Chances and Threats of Traditional Culture in the Globalising World).

The conference ended with a panel discussion whose participants unanimously expressed their support for the need of reaffirming both local and global responsibility in a broader axiological context that strengthens inter-personal relations and hence opens the room for dialogue and respect. Stefan Konstańczak in his lecture: The Responsibility of Intellectual Elites for Global and Local Culture searched for an exemplary axiological trait in the "aristocratic" in the context of values attitude of Henryk Elzenberg. Other prelectors directly referred to values constituting public space, including trust, a fundamental value that is in a deficit today (Krzysztof Wielecki: Responsibility, Trust, Action; Anna Drabarek: Trust as Fundamental Value of Public Space in the Local Dimension).

An axiological accent that ended the proceedings can be treated as a conclusion of the conference, which showed that reflection on the locality and globality cannot be detached from values because - as it was emphasised many times by the prelectors - they give the proper direction to human action.

At the conference a new Internet-based Academic journal was introduced, namely "Studies in Global Ethics and Global Education" published by the Maria Grzegorzewska University. The journal will publish articles thematically related with the problems addressed by the presentations delivered at the conference. 